\title{
Performance Prediction of a Pressurized Entrained Flow Ultra-Fine Coal Gasifier
}

\author{
P. P. Mashingo*, G. R. John, C. F. Mhilu \\ Department of Mechanical, Industrial Engineering College of Engineering, Technology University of Dar es \\ Salaam, Dar es Salaam, Tanzania \\ Email: mashingopp@hotmail.com
}

Received 12 December 2013; revised 13 January 2014; accepted 20 January 2014

Copyright $@ 2014$ by authors and Scientific Research Publishing Inc.

This work is licensed under the Creative Commons Attribution International License (CC BY).

http://creativecommons.org/licenses/by/4.0/

(c) ()

\begin{abstract}
Gasification is an efficient method of producing clean synthetic gas which can be used as fuel for electric generation and chemical for industries use. Gasification process simulation of coal inside a generic two-stage entrained flow gasifier to produce syngas was undertaken. Numerical simulation of the oxygen blown coal gasification process inside a two-stage entrained coal gasifier is studied with the commercial CFD solver ANSYS FLUENT. The purpose of this study is to use CFD simulation to improve understanding of the gasification processes in the state of art two-stage entrained flow coal gasifier. Three dimensions, Navier-Stokes equations and species transport equations are solved with the eddy-breakup reaction model to predict gasification processes. The influences of coal/water slurry concentration and $\mathrm{O}_{2} /$ coal ratio on the gasification process are investigated. The coal-to-water slurry concentrations in this study were 0.74 and $0_{2} /$ coal ratio is 0.91. Coal slurry fed the predicted concentration of $47.7 \%$ and $C O$ was $25 \%$ with higher syngas heating value of $27.65 \mathrm{MJ} / \mathrm{kg}$. The flow behavior in the gasifier, especially the single fuel injection design on the second stage, is examined and validated against available data in the literature.
\end{abstract}

\section{Keywords}

Gasification; Simulation; Mathematical Modeling; CFD; Species

\section{Introduction}

Coal reserves represent the largest of the world's energy resources estimated about 900,000 billion tons [1]. About $41 \%$ of the world's electricity is provided by coal and an increase to $44 \%$ is expected by 2030 . Coal is the only fossil fuel with the reserves to stay for more than 200 years at the current production rates compared to oil

${ }^{*}$ Corresponding author.

How to cite this paper: Mashingo, P.P., John, G.R. and Mhilu, C.F. (2014) Performance Prediction of a Pressurized Entrained Flow Ultra-Fine Coal Gasifier. Modeling and Numerical Simulation of Material Science, 4, 70-77.

http://dx.doi.org/10.4236/mnsms.2014.42009 
and natural gas reserves which are in the order of 40 years and 60 years [2]. Therefore, it is expected that coal will remain a potential source of energy for decades to come. Unfortunately, coal contains undesirable systems such as nitrogen and sulfur. Burning coal will release these impurities in form of $\mathrm{NO}_{\mathrm{x}}$ and $\mathrm{SO}_{\mathrm{x}}$ into the air, which can react with the air's water vapor and form acid rain. In addition, burning coal produces carbon dioxide. Carbon dioxide in the atmosphere can trap the earth's heat causing the greenhouse effect and changes the earth's climate. Hence, to reduce emission of $\mathrm{NO}_{\mathrm{x}}$ and $\mathrm{SO}_{\mathrm{x}}$, it is important to improve the efficiency of coal power generation.

The above calls on improving the coal combustion efficiency and developing new technology that can extend the usability of coal more cleanly. The high temperature gasification is one of the cleanest and most thermally efficient ways to convert the energy content from coal feeds stock into a useful product. Entrained flow coal gasifiers have been widely used in coal gasification technologies because of their high capacity and steady good performance. Also the elevated high temperature in the entrained flow gasifier guarantees a high carbon conversion in short residence time. [3] and [4] investigated the coal gasification process under different parameters, such as mixing fluctuations, which affected the volatile and gasification reaction and significantly influenced the temperature and syngas composition. However, the simulation capability for gasification was limited due to the implication of gasification reaction and low quality of the syngas produced. Computational fluid dynamics (CFD) model offers a powerful solution for understanding and improves gasification processes. Over the past decades, CFD modeling has played an important role in optimizing the performance of pulverized coal for power generation [5]. This paper is focused on the modeling of coal gasification processes to improve the understanding of the gasification processes in a two-stage entrained flow coal gasifier.

\section{Model Description and Methodology}

The proximate and ultimate analyses of coal particle are used is depicted in Table 1.

The modeling of coal gasification in the entrained flow gasifier is conceptually divided into four subprocesses: inert heating and moisture release, devolatilization, gas phase reactions, char gasification. These physical and chemical processes are described in the following.

\subsection{Inert Heating and Moisture Release}

Inert heating and moisture release the inert heating is applied when particle temperature is lower than a predefined devolatilization temperature $T_{d e v}$ which is about $350^{\circ} \mathrm{C}$. This conditions may written as

$$
T_{p}<T_{d e v}
$$

Table 1. Proximate and ultimate analysis of Kiwira Coal.

\begin{tabular}{|c|c|c|}
\hline Parameter & Standard & Value (\%) \\
\hline \multicolumn{3}{|c|}{ Proximate analysis } \\
\hline Moisture & \multirow{4}{*}{$\begin{array}{c}\text { ASTM } \\
\text { D-3172 }\end{array}$} & 3.21 \\
\hline Volatile matter & & 37.65 \\
\hline Ash & & 25.44 \\
\hline Fixed carbon & & 33.7 \\
\hline \multicolumn{3}{|c|}{ Ultimate analysis (dry basis) } \\
\hline C & \multirow{5}{*}{$\begin{array}{c}\text { ASTM } \\
\text { D-3176 }\end{array}$} & 81.01 \\
\hline $\mathrm{H}$ & & 5.79 \\
\hline $\mathrm{N}$ & & 1.71 \\
\hline$S$ & & 1.39 \\
\hline $\mathrm{O}$ & & 10.46 \\
\hline \multicolumn{2}{|c|}{ Higher heating value (MJ/kg) } & 27.62 \\
\hline
\end{tabular}


For Equation (1) inert hearting occurs when the gas temperature $T_{p}$ is less that devolatilization temperature $T_{\text {dev }}$. During heating of the particles, heat transfer is only due to convection and radiation at the particle surface which is represented by the equation bellow:

$$
m_{p} C_{p} \frac{d T_{p}}{d t}=h \cdot A_{p}\left(T_{\infty}-T_{p}\right)+\varepsilon_{p} A_{p} \sigma\left(T_{R}^{4}-T_{p}^{4}\right)
$$

where $m_{p}=$ mass of coal particle,

$C_{p}=$ heat capacity of coal particle,

$T_{\infty}=$ gas temperature in the gasifier reactor,

$h=$ heat transfer coefficient,

$\varepsilon_{p}=$ emissivity of coal particle,

$\sigma=$ Stefan-Boltman constant,

$T_{R}=$ radiation temperature.

During heating particles no chemical reactions or mass transfer processes take place. The moisture released is added to the gas phase species continuity equation as a source term. The vaporization energy required for moisture release is extracted from the continuous phase.

\subsection{Devolatilization}

The devolatilization has a significant impact on the gasification stability and ignition. When the particle has reached an offset temperature for devolatilization $T_{\text {dev }}$ volatile matter release begins this phenomenon called devolatilization. The main species released during the volatile break up are $\mathrm{CO}, \mathrm{CO}_{2}, \mathrm{H}_{2}, \mathrm{CH}_{4}, \mathrm{O}, \mathrm{N}_{2}, \mathrm{H}_{2} \mathrm{O}$, and $\mathrm{H}_{2} \mathrm{~S}$. When the particle has reached an offset temperature for devolatilization, $T_{\text {dev }}$ volatile matters release begins. Equation (3) remains in effect until all the volatile matter has volatilized to the gas phase.

$$
T_{p}>T_{d e v}
$$

The heat transfer to the particle during the devolatilization process governs the contributions from convection, radiation and latent heat consumed during devolatilization and it is written as shown in Equation (4).

$$
m_{p} C_{p} \frac{d T_{p}}{d t}=h \cdot A_{p}\left(T_{\infty}-T_{p}\right)+\frac{d m_{p}}{d t} H_{f g}+\varepsilon_{p} A_{p} \sigma\left(T_{R}^{4}-T_{p}^{4}\right)
$$

where; $H_{f g}$ latent heat evaporation of coal particle, $\frac{d m}{d t}$ is the rate of change of the particle.

\subsection{Char Gasification}

The char gasification reactions take place after all volatiles in the coal particles are released. These reactions are exothermic and take place at high operating temperatures above $1000^{\circ} \mathrm{C}$ and take place until all char particles react the gasifier. The heterogeneous reactions are modeled by multiple surface reaction mechanism which already available as a sub-model in [6]. The chemical reactions in the gas-solid interaction include reaction of char particle with $\mathrm{O}_{2}, \mathrm{CO}_{2}$ and $\mathrm{H}_{2} \mathrm{O}$ and the major products of surface reactions are $\mathrm{CO}$ and $\mathrm{H}_{2}$. The reactions considered in this model along with reaction rate information are summarized in Table 2.

\subsection{Gas Phase Reaction}

The gas phase reactions take place in the reduction and gasification zone of the entrained flow gasifier including carbon dioxide, steam formation, water gas shift reaction and methane steam reactions. The homogeneous reactions are modeled using global reaction kinetics to describe gas phase chemistry and the kinetic parameters [7], [8] and [9], and [8] are given in Table 1. The turbulence chemistry interaction is modeled using a finite rate/ eddy dissipation model, a built in module in [6], where the effective reaction rate is defined by considering the minimum between turbulence dissipation rate and chemical reaction rate.

The kinetic rate expressions for global reactions for both heterogeneous and homogeneous reactions are given by Arrhenius relationship as:

$$
k=A T^{n} e(-E / R T)
$$


Table 2. Kinetic rate parameters for reactions.

\begin{tabular}{cccc}
\hline Reaction & $A$ & $E(\mathrm{~J} / \mathrm{kmol})$ & $R_{n}$ \\
\hline $\mathrm{C}+1 / 2 \mathrm{O}_{2} \rightarrow \mathrm{CO}$ & 0.86 & 1.49 & 1 \\
$\mathrm{C}+\mathrm{H}_{2} \mathrm{O} \rightarrow \mathrm{CO}+\mathrm{H}_{2}$ & 1.33 & 1.47 & 2 \\
$\mathrm{C}+\mathrm{CO}_{2} \rightarrow 2 \mathrm{CO}$ & 4.4 & 1.62 & 3 \\
$\mathrm{C}+2 \mathrm{H}_{2} \rightarrow \mathrm{CH}_{4}$ & $1.18 \times 10^{-5}$ & 1.49 & 4 \\
\hline $\mathrm{CO}+1 / 2 \mathrm{O}_{2} \rightarrow \mathrm{CO}_{2}$ & $2.2 \times 10^{12}$ & 1.67 & 5 \\
$\mathrm{H}_{2}+1 / 2 \mathrm{O}_{2} \rightarrow \mathrm{H}_{2} \mathrm{O}$ & $6.8 \times 10^{15}$ & 1.67 & 6 \\
$\mathrm{CH}+1 / 2 \mathrm{O}_{2} \rightarrow \mathrm{CO}_{4}$ & $3 \times 10^{8}$ & 1.26 & 7 \\
$\mathrm{CO}+\mathrm{H}_{2} \mathrm{O} \leftrightarrow \mathrm{CO}_{2}+\mathrm{H}_{2}$ & $2.65 \times 10^{-2}$ & $3.96 \times 10^{-5}$ & 8 \\
$\mathrm{CH}_{4}+\mathrm{H}_{2} \mathrm{O} \leftrightarrow \mathrm{CO}^{2}+3 \mathrm{H}_{2}$ & $5.12 \times 10^{-14}$ & $2.74 \times 10^{-4}$ & 9 \\
\hline
\end{tabular}

$k=A e^{-E / R T}$ where $k=$ rate constant, $A=$ is the pre exponential constants, $E=$ activation energy, $R=$ is the universal gas constant, $T=$ is the temperature.

\section{Multi-Phase Modeling}

As mentioned earlier, the numerical method is based on a coupled Eulerian-Lagrangian formulation in which the conservation equations of the continuous phase are modeled in Eulerian frame and the coal particle trajectory is predicted in a Lagrangian reference frame. The governing equations for mass, momentum, energy and species of the continuous phase can be transformed into a general transport equation of dependent variable $\phi$, written as follows:

$$
\frac{\partial}{\partial t}(\rho \phi)+\frac{\partial}{\partial x_{j}}\left(\rho \phi u_{j}\right)=\frac{\partial}{\partial x_{j}}\left(\Gamma_{\varphi} \frac{\partial \phi}{\partial x_{i}}\right)+S_{\phi}
$$

where $\Gamma_{\phi}$ and $S_{\phi}$ are the diffusion coefficient and the source term, respectively and these are specific to a particular meaning of $\phi$ as shown in Table 3.

\section{Results and Discussion}

Figure 1 shows the velocity vectors on the different position at the gasifier plane. The velocity vectors on the horizontal planes shows that the velocity near the center region of the gasifier is higher compared to the velocity in the region near the wall. Also observed in the combustor the velocity is intensity recirculating which will increase the residence time for a trapped flow and provide mixing between the unreacted coal slurry and hot gases. The observed velocity spikes about two meters gasifier height (gasifier center line) is likely due to the complex interaction of turbulent rotating flow emanating from the two bottom tangential injections causing some oscillations.

Figure 2 shows temperature distributions at different position in plane of the gasifier. Maximum gas temperature in the combustor reaches about $2900^{\circ} \mathrm{C}$. The dominant reaction in the combustor is intense char combustion and gasification reaction. Oxygen is completely depleted through the char combustion in the combustor. Gasification reactions are taking place in the upper stage on the gasifier (reductor) where most of syngas is formed. The oxidation and combustion reactions generate significant heat and temperature in the middle of first stage is rise to $2390^{\circ} \mathrm{K}$. When the hot syngas transports into the second stage, it reacts with the coal slurry, which is fed from the upper stage. There is no additional oxidant being injected into the second stage of the gasifier but slurry is injected.

Figure 3(a) shows the contours of temperature and mole fractions of $\mathrm{H}_{2}$ along mid plane in the gasifier. The $\mathrm{H}_{2}$ concentration increases along the height of the gasifier reaching maximum towards the outlet. The $\mathrm{H}_{2}$ increases rapidly in the last portion of the gasifier height due to drop of temperature resulting in most of the reac- 
Table 3. Variables for the generalized transport equations.

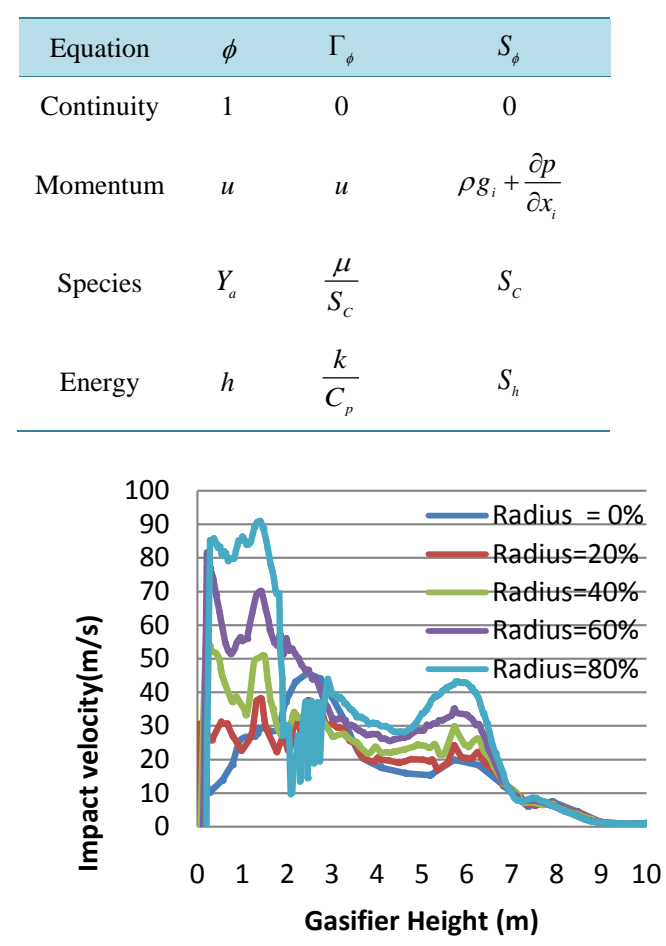

Figure 1. Velocity vector on the different position at the gasifier $\mathrm{x}-\mathrm{y}$ plane.
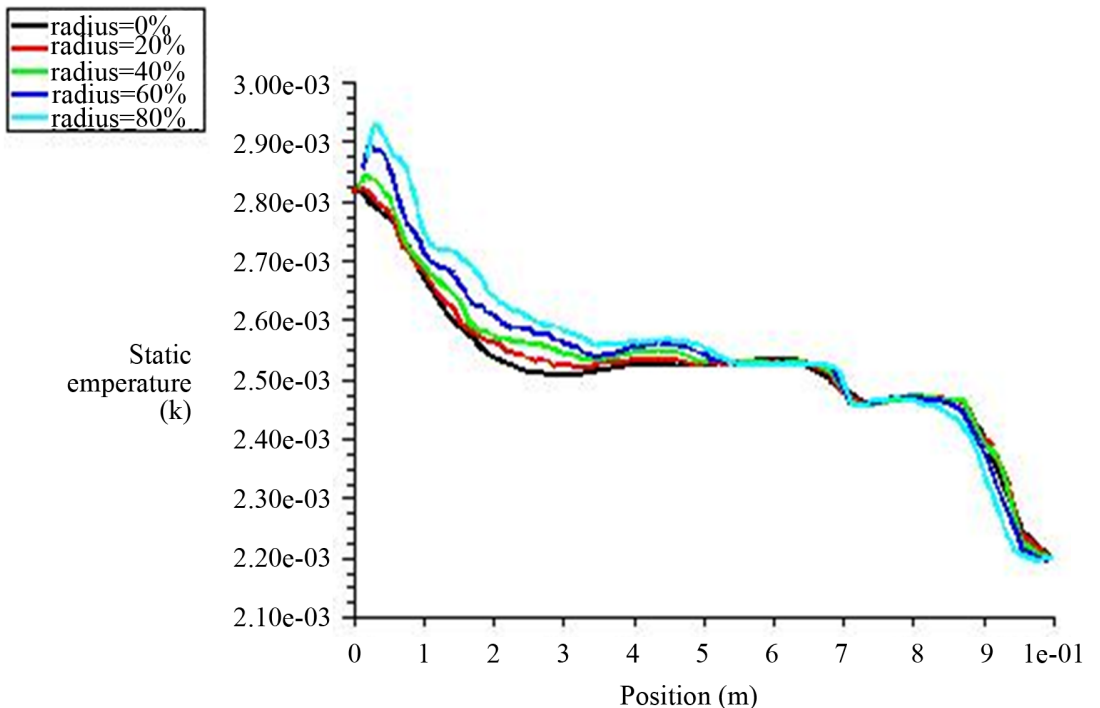

Figure 2. Distribution of the temperature at different position in vertical plane.

tions consuming $\mathrm{H}_{2}$ do not taking place. On right hand side shows the lowest $\mathrm{H}_{2}$ consumed at first stage of gasifier during combustion process, and most of $\mathrm{H}_{2}$ form between 2 and 9 meters of the gasifier height. The last portion of the gasifier the $\mathrm{H}_{2}$ increased rapidly due to drop of temperature. Figure 3(b) shows mole fractions of $\mathrm{CO}$ at different position in the gasifier plane. Combustion occurs when coal slurry and oxidant are injected into the first stage of gasifier (combustor). The carbon and oxygen react immediately and generate CO. When the CO is transported into the upper stage of the gasifier, further reacts occur. The lowest CO at first stage of gasifier 


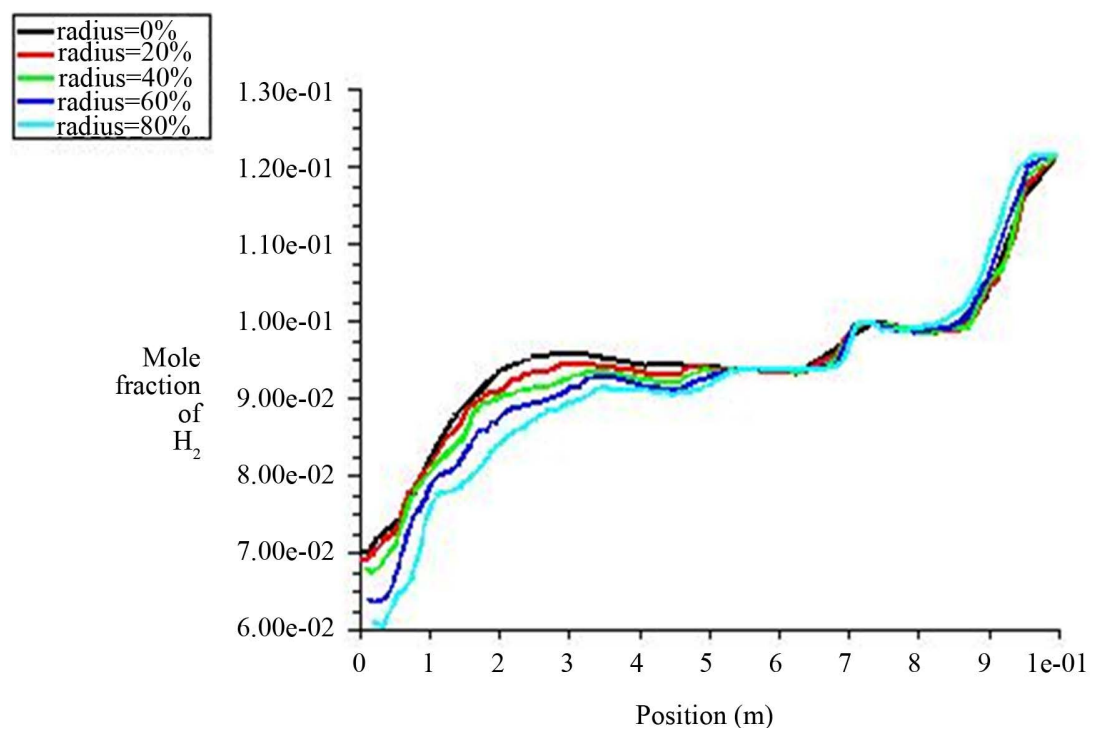

(a)

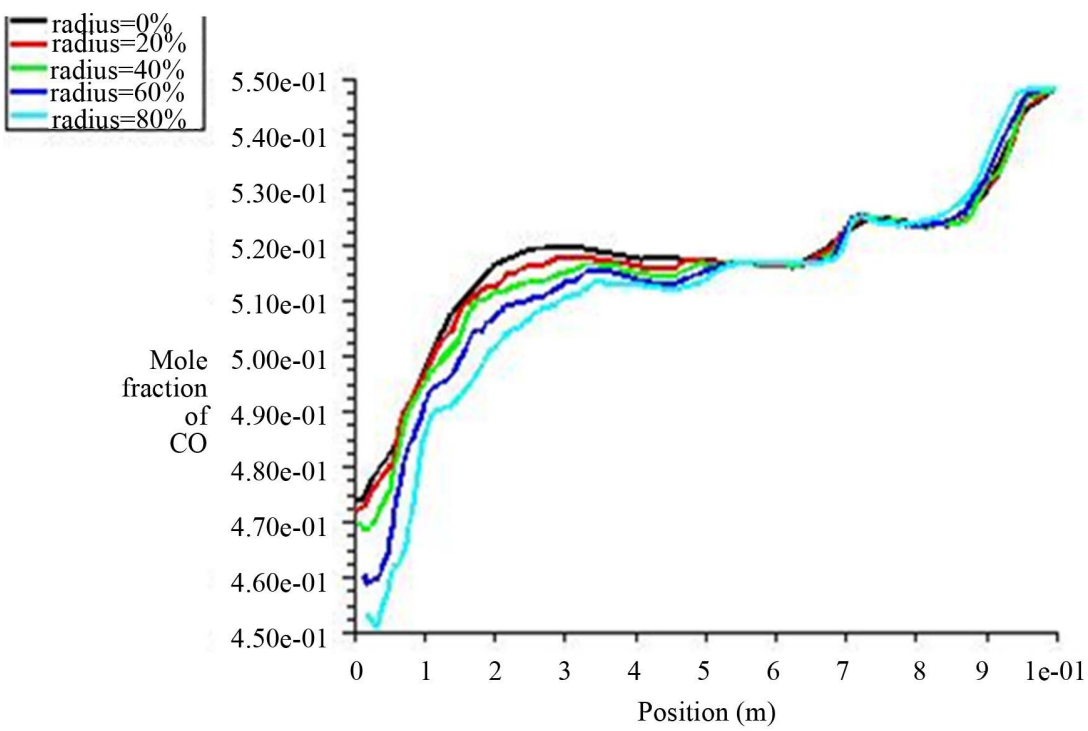

(b)

Figure 3. (a) Distribution of mole fraction of $\mathrm{H}_{2}$ at different position plane along gasifier; (b) The average mole fraction of $\mathrm{CO}$ at different position in the gasifier plane.

because the CO is consumed during combustion process as observed in Figure 3(b). CO increases rapidly in the last portion of the gasifier height due to drop of temperature resulting in most of the reactions consuming CO do not taking place.

The complete char combustion taking place in the first stage of the gasifier produces a large amount of $\mathrm{CO}_{2}$ shown at the bottom of the reactor. As observed on the figure on right hand side (Figure 4), around 2 to 9 meters height of gasifier the $\mathrm{CO}_{2}$ is nearly constant there after drops down suddenly.

\section{Conclusion}

A 3D axis-symmetric CFD model is developed and the predictions of species mole fraction distribution in $x-y$ axial direction are compared. The model is able to predict the overall trend of species distribution inside the entrained flow gasifier. Better quantitative agreement was found with $\mathrm{H}_{2}, \mathrm{CO}, \mathrm{CO}_{2}$, and $\mathrm{H}_{2} \mathrm{O}$ as compared to the experimental values from the work of Martin et al. (2002) [10]. The percentage deviations are 11\%, 7\%, 5\% and 


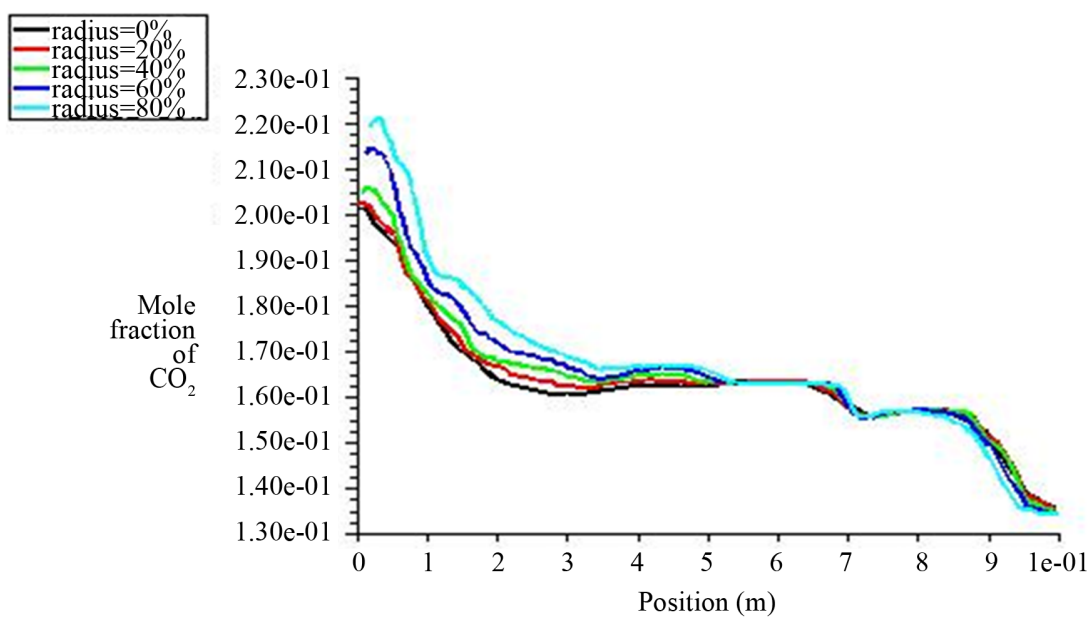

Figure 4. The average mole fraction of $\mathrm{CO}_{2}$ at different position in the gasifier plane.

$1 \%$ respectively. Detailed species distribution inside the gasifier is shown and the underlying physical and chemical processes are delineated.

\section{Acknowledgements}

I would like to thank the College of Engineering and Technology (CoET) of University of Dar es Salaam for its, financial support and the assistance to my research work.

\section{References}

[1] BP (2007) Statistical Review of World Energy. www.bp.com/staticalreview

[2] Mkilaha, I.S.N. and John, G.R. (2001) Prospects of Coal Utilization in Tanzania. IET Seminar Proceedings, Arusha 30-38.

[3] Silaen, A. and Wang, T. (2010) Investigation of the Coal Gasification Process under Various Operating Conditions inside a Two-Stage Entrained Flow Gasifier. Proceedings of the 27th International Pittsburgh Coal Conference, Istanbul, 11-14 October 2010, 11-14.

[4] Wen, C.Y. and Chaung, T.Z. (1979) Entrainment Coal Gasification Modeling. Industrial \& Engineering Chemistry Process Design and Development, 18, 684-695. http://dx.doi.org/10.1021/i260072a020

[5] Wantabe, H. and Otaka, M. (2006) Numerical Simulation of Coal Gasification in Entrained Flow Coal Gasifier. Fuel, 85, 1935-1943. http://dx.doi.org/10.1016/j.fuel.2006.02.002

[6] Ansys Inc. (2009) Ansys Fluent Manual. Ansys Inc., Cecil Township.

[7] Brown, B.W., Smoot, L.D., Smith, P.J. and Hedman, P.O. (1988) Measurement and Prediction of Entrained-Flow Gasification Processes. AIChE Journal, 34, 435-446. http://dx.doi.org/10.1002/aic.690340311

[8] Chen, X., Horio, M. and Kojima, T. (2000) Numerical Simulation of Entrained Flow Gasifiers. Chemical Engineering Science, 55, 3861-3874. http://dx.doi.org/10.1016/S0009-2509(00)00030-0

[9] Liu, L., Zhao, H., Wang, B., Xu, D., Jiang, L. and Zheng, C. (2008) Numerical Simulation of Gasification Processes. Energy Fuels, 22, 898-905.

[10] Martin, K.D., Zumao, C.T., Linjewile, C.L. and Adel, F. (2002) CFD Modeling for Entrained Flow Gasifiers in Vision 21 Systems. Reaction Engineering International Online. http://www.reaction-eng.com 


\section{Nomenclature}

\section{Abbreviation}

CFD: Computational Fluid Dynamic

\section{Symbols}

$T_{p}$ : Particle temperature

$T_{d e v}$ : Devolatilization temperature

$T_{R}$ : Radiation temperature

$T_{\infty}$ : Gas temperature in the gasifier reactor

A: Surface area

$E$ : Activation energy

$R$ : Universal gas constant

$T$ : Temperature

$\varepsilon_{p}$ : Emissivity of coal particle

$C_{p}$ : Heat capacity of coal particle

$m_{p}$ : Mass of coal particle

$\sigma$ : Stefan-Boltman constant

$R_{n}$ : Reaction number 